\title{
The impact of the implementation of the financial shared service model on Haier Smart Home
}

\author{
Zhuang Yani*1 \\ ${ }^{1}$ Beijing Jiaotong University
}

\begin{abstract}
With the development of economic globalization, companies continue to expand through mergers, and problems such as low operating efficiency and increased management costs have begun to emerge. Traditional financial management models have been difficult to adapt to the development of enterprises. Therefore, in order to operate branches more efficiently and improve operational efficiency, enterprises have begun to vigorously develop financial shared service models. This article analyzes the impact of Haier Smart Home after the implementation of the financial shared service model, and explains the necessity of implementing the financial shared service model, hoping to attract more large enterprise groups to build a financial shared service model.
\end{abstract}

\section{INTRODUCTION}

With the enterprises going out actively, the scale of enterprises is also expanding, leading to longer and longer management chains of enterprises, and problems such as low operating efficiency, waste of resources, and increased management costs have gradually emerged. The traditional financial management model has been difficult to adapt to the development of the enterprise. In order to change this status quo, enterprises have begun to vigorously develop financial shared service models.

In the 1980s, foreign countries began to implement the financial shared service model. Therefore, the theoretical system for the financial shared service model research is relatively complete. However, due to a late start in China, the exploration of this model is not mature enough compared to foreign countries. As China has begun to actively promote the strategy of enterprise grouping, many domestic enterprises have undergone mergers, and the number of subsidiaries has gradually increased. Subsidiaries and branches have established supporting organizational structure systems, which account for a large amount of enterprise costs. Due to the different management systems and financial standards of branches and subsidiaries, enterprises are facing difficulties in information collation, it is difficult to establish information systems, and they cannot make correct decisions based on enterprise problems and market needs, which restricts the development of enterprises. Therefore, if companies want to survive and develop further, they must carry out changes in financial management models. With the advent of the "big data" era, more and more large domestic enterprise groups have begun to transform from traditional financial management models to financial shared service models.

Foreign scholar Fritze AK ${ }^{[1]}$ (2015) pointed out that the financial shared service model, as a new type of financial management model, has a significant impact on controlling corporate costs, improving corporate service quality and work efficiency. Squilla Betal [2] (2017) believes that in the course of practice, the financial shared service model tries to consolidate the administrative functions of its organization. Although the financial shared service model can reduce costs, it also has certain shortcomings. Daher GP ${ }^{[3]}$ (2017) studied the concept of the financial shared service model and the reasons for its formation, and described the construction framework of the financial shared service center, including the location selection and organizational structure. Domestic scholar Zhang Yanhui ${ }^{[4]}$ (2019) elaborated on the changes that companies have made after implementing the financial shared service model, including improving capital efficiency, providing data support for tax planning, and realizing financial value creation. Foreign scholars have formed a relatively complete theoretical system for the study of the financial shared service model. However, due to the late start of domestic scholars, the research on the financial shared service model is not deep enough compared with foreign research. The research focus is on the case analysis method. Research on the application of the financial sharing service model in enterprises is carried out, and there is little research on the impact and change of enterprises after the implementation of the financial sharing model.

This paper analyzes the changes after the implementation of the financial shared service model by Haier Smart Home by setting indicators, further deepens the exploration of the financial shared service model, and

e-mail: hndxzyn@163.com 
explains the necessity of implementing the financial shared service model, hoping to attract more large domestic enterprise groups Implement the financial shared service model.

\section{METHODS}

Since 2007, Haier Smart Home have begun to explore the financial sharing service model. Therefore, through the compilation of the financial reports of Haier Smart Home from 2006 to 2018, the effective financial data of the twelve years has been selected to explore the implementation of the financial sharing service model of Haier Smart Home. First of all, by setting the ratio of total assets to financial personnel, and the ratio of total assets to management personnel, it is used to observe the impact on the work efficiency of corporate personnel after the implementation of the financial shared service model. The greater the amount of assets allocated and managed by unit managers or financial personnel, it means that the company can use fewer personnel to manage the company's financial work, and then know that the company's operating efficiency is high; secondly, through the management of financial personnel and management Calculate the growth rate of personnel and set the ratio of management expenses to total assets, observe whether the reduction of personnel after the implementation of the financial shared service model of Haier Smart Home has reduced labor costs, and study whether the financial shared service model reduces corporate supervision costs; finally, By selecting the asset-liability ratio as a financial indicator and setting the ratio of accounts receivable to total assets, we can observe the changes in risk management and control capabilities of enterprises after implementing the financial shared service mode ${ }^{[5]}$.

\section{RESULTS}

\subsection{Improve the operational efficiency of enterprises}

Since 2007, after implementing the financial shared service model, Haier Smart Home has used the platform of the financial shared service center to efficiently process financial work, and its operational efficiency has been significantly improved. From Figure 1, we can observe the trend of these two ratios from 2006 to 2018. From 2006 to 2009, the two set ratios have been showing an upward trend, indicating that the implementation of the financial shared service model has improved the work of the enterprise effectiveness. However, in 2010, the ratio of total assets to financial staff dropped sharply. The reason is that with the expansion of the scope of the financial shared service center and the scale of the enterprise, the original financial staff has been unable to support the business volume of the enterprise with a relatively large scale. Therefore, in order to ensure the normal operation of the financial shared service model, the company can only maintain operations by increasing financial staff, expanding the original 151 to 525 . Due to the rapid expansion of the financial staff, the ratio of total assets to financial staff has dropped greatly. But judging from the overall trend, the overall operating efficiency of enterprises is still on the rise. Haier Smart Home began to build a financial shared service model in 2007. As of 2018, the ratio of total assets to management personnel and financial personnel has increased significantly. This shows that as the financial shared service model continues to mature, it is important for enterprises. Operational efficiency has also played a role in promoting, which is conducive to the efficient operation of enterprises.

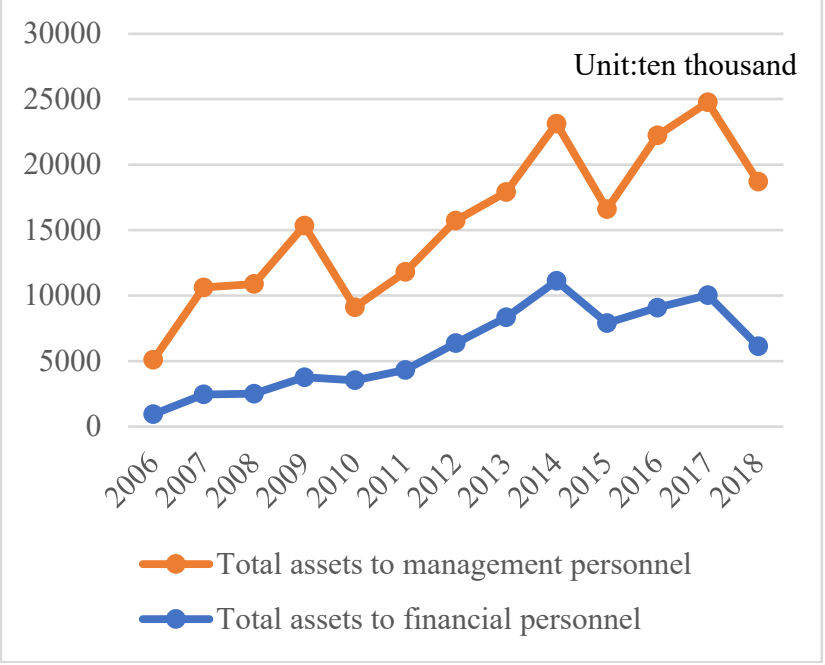

Figure1 The trend of the ratio of total assets to financial personnel and management personnel

\subsection{Reduce costs}

After Haier Smart Home implements the financial shared service model, it also has a certain significance for the reduction of enterprise operating costs. It can be seen from Figure 3 that in 2007, the growth rate of Haier Smart Home's financial staff dropped sharply, and showed a negative growth, indicating that when the financial shared service model was first established, Haier Smart Home carried out large-scale layoffs to pave the way for flat management, and reduce the labor cost of the enterprise. In the process of the continuous development and construction of the financial shared service model, because the original scale of personnel is difficult to support the development of the enterprise and the operation of the financial shared service model, corporate financial personnel and management personnel increased sharply in 2010 to maintain corporate financial sharing Smooth operation of the service center. From 2011 to 2014, the financial shared service model has entered a stable period of development. The growth rate of corporate financial personnel has been maintained at around $0 \%$ growth rate, and management expenses have also been maintained at a relatively low growth rate, indicating that the company is implementing financial After the shared service model, centralizing the dispersed financial functions can indeed effectively reduce costs. In 2015 , with the further development of the company, the expansion of the company's business, and the further expansion of financial personnel and management 
personnel, but in 2016 it again showed a downward trend. However, individual phenomena did not affect the overall trend. In general, Haier Smart Home's financial sharing services will be scattered among the financial functions of various subsidiaries, which can indeed greatly reduce labor costs and expenses.

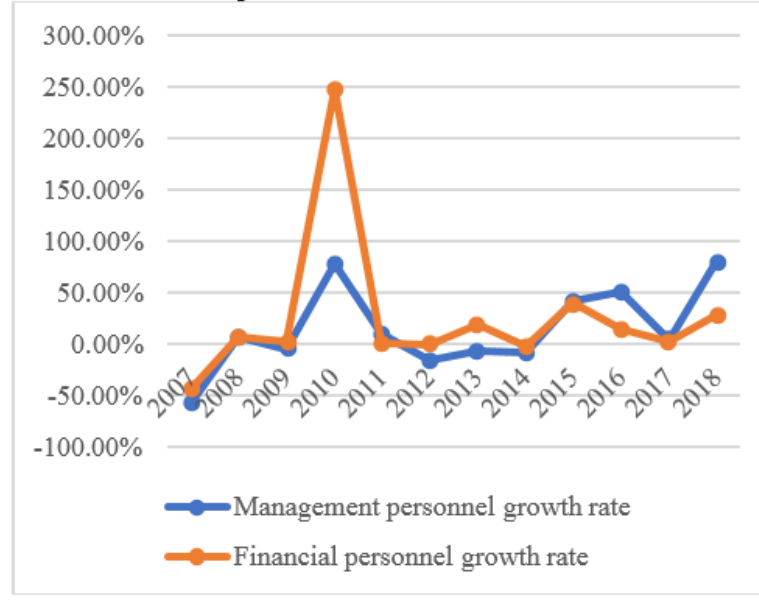

Figure2 Trend of growth rate of management expenses, management personnel and financial personnel

The implementation of the financial shared service model is also conducive to reducing the cost of supervision of enterprises. Due to the construction of the financial shared service model, enterprises carry out flat management, reduce the organizational structure, and greatly reduce the administrative staff, thereby reducing the cost of supervision. Administrative expenses are part of the regulatory cost, and the administrative expenses are directly proportional to the regulatory costs. Therefore, by setting the ratio of the administrative expenses to the total assets to study the impact of the implementation of the financial sharing service model on the regulatory costs, when the ratio declines, it indicates that the financial sharing The service model plays a role in reducing the cost of supervision, and vice versa. It can be seen from Figure 3 that during the initial stage of the financial shared service model, the ratio of management expenses to the total assets showed a significant upward trend, indicating that the regulatory cost has not been effectively controlled in the initial stage. Not perfect, so growth is normal. Since 2009, the ratio has begun to show a downward trend, indicating that the cost of supervision has been effectively controlled. As Haier Smart Home continues to mature in the construction of the financial shared service model, the ratio of management expenses to total assets continues to decline, indirectly reflecting the continuous decline in regulatory costs, indicating that the financial shared service model is of great significance for companies to reduce regulatory costs.

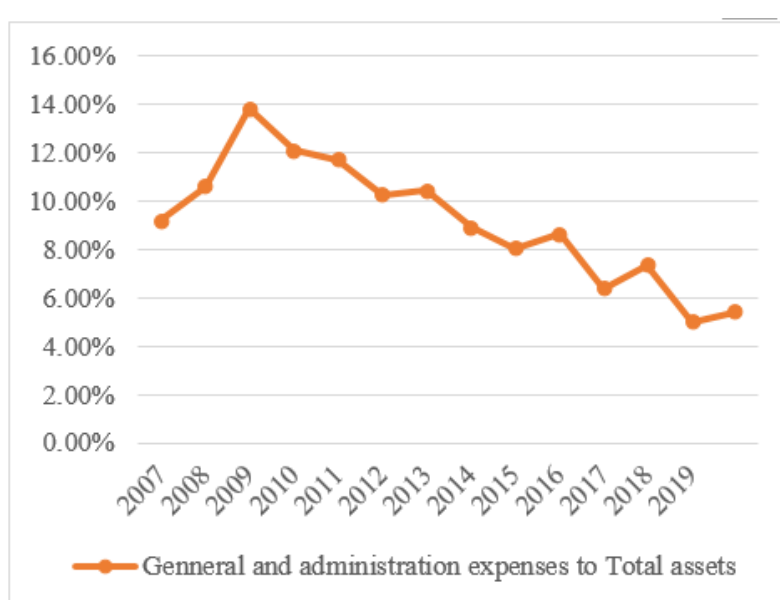

Figure3 Trend of genneral and administration expenses to total assets

\subsection{Improve corporate risk management and control capabilities}

In the course of business operations, in order to maximize benefits, companies will leverage financial leverage through debt to obtain greater returns, but in order to ensure the safety of corporate capital operations, risk management must be carried out. Therefore, this article selects the asset-liability ratio as a financial indicator to observe the changes in the risk management and control capabilities of enterprises after implementing the financial shared service model. When a company's debt-to-asset ratio is too high, its financial risk will increase accordingly. The financial shared service center can monitor the high risk of the company and adjust the scale of debt to reduce the risk; conversely, when the debt-toasset ratio At a lower ratio, although the financial risk is lower, the benefits obtained through financial leverage are also less. At this time, the financial shared service center can more effectively monitor this situation and make adjustments to achieve the greatest value.

As shown in Figure 4, from 2007 to 2009, the company's asset-liability ratio has been on an upward trend, but it is below the industry average, indicating that it has not fully utilized financial leverage to obtain benefits. With the development and maturity of the financial shared service model, based on the data support of the financial shared service center, Haier Smart Home obtains financial leverage benefits by expanding the scale of debt. In 2010 and 2011, the debt-to-asset ratio was as high as $70.95 \%$. At this time, the financial risk was already at a relatively high level, and companies needed to adjust the scale of debt to reduce risk. Therefore, since 2012, companies have adjusted their debt scale to reduce business risks. As can be seen from Figure 4, as the construction of the financial shared service model continues to mature, the company's asset-liability ratio has not only declined year by year, but has also maintained a stable level. When the financial risk of the enterprise is low, the financial leverage income is also low, and the enterprise again adjusts to expand the scale of debt. It can be seen that by building a financial shared service model, Haier Smart Home can adjust the financial risk and debt 
scale of the company based on its powerful information system, reduce the company's operating risk, monitor the company's operating status in real time, and provide feedback to the company. Make adjustments to its business strategy to maximize the benefits of the company.

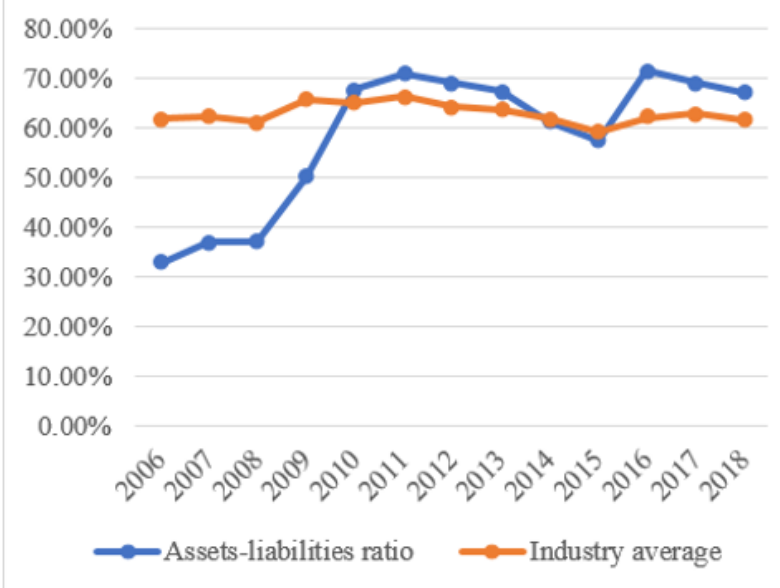

Figure4 Haier Smart Home's asset-liability ratio and industry average change trend

Enterprise accounts receivable is also an important factor that causes financial risks. The greater the proportion of accounts receivable in assets, the greater the possibility of bad debts. Therefore, it is observed by setting the ratio of accounts receivable to total assets. The higher the ratio, the greater the possibility of bad debts in accounts receivable, and the greater the financial risk, and vice versa. Since the company began to build a financial sharing service model in 2006, the ratio of accounts receivable to total assets has dropped sharply from $17.67 \%$ to $5.17 \%$. This is due to the establishment of a risk management module for accounts receivable. Independent accounting, supervision and control can reduce the bad debt risk of accounts receivable, thereby reducing the business risk of the enterprise. Since 2007, the ratio of accounts receivable to total assets has been maintained at a relatively stable level, indicating that the financial shared service center has played a good role in controlling accounts receivable and effectively reduced the financial risks of the enterprise.

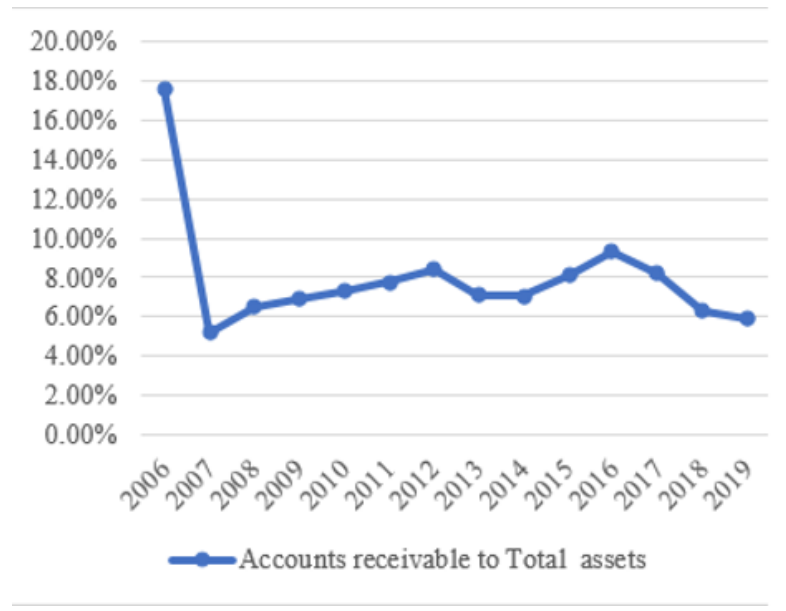

Figure 5 Trend of accounts receivable to total assets

\section{CONCLUSION}

With the development of economic globalization, companies are actively "going out." The expansion and mergers of companies have led to longer and longer management chains. Traditional financial management models no longer adapt to the development of companies. Therefore, driven by the background of big data, The financial shared service model has become a new model of financial management transformation. As the first enterprise in China to establish a financial shared service model, Haier Smart Home has compiled the twelve-year annual report of Haier Smart Home and observed the impact of Haier Smart Home after the implementation of the financial shared service model from various vertical ratios. Due to the organizational restructuring and process Reengineering, centralizing financial staff to the financial shared service center to process basic financial tasks, reducing the cost of the enterprise and improving the efficiency of operation. At the same time, through the analysis of the asset-liability ratio and the ratio of accounts receivable to total assets, it can be known that the financial shared service center can detect the risks faced by the enterprise through the information system, thereby improving the enterprise's risk management and control capabilities.

As a new type of financial management model, the financial shared service model will benefit more and more large enterprise groups in the future. It is also hoped that this article can attract more companies to build a financial shared service model.

\section{ACKNOWLEDGEMENTS}

First of all, I would like to thank my instructor in particular, thank you for giving me careful guidance from the topic selection of the paper, the frame design including the writing of each chapter.

Secondly, I would also like to thank my friends and classmates for their encouragement and support in writing the paper, and for the great inspiration they gave me, and thank them for reaching out to me when I was exhausted and at a loss. At the same time, I also want to thank the authors who appeared in the references. Through the study and understanding of their research articles, I have a better starting point for the content of the research.

Finally, I would like to express my gratitude to all the experts who took the time to review and comment on this article.

\section{REFERENCES}

1. Fritze AK.(2015)Chang Management be Shared Service Center.Zeitschrift Fur Erfolgsorientierte Unternehmenssteuerung, 27(7):425-427.

2. Squilla Betal.(2017)Research Shared Services:A Case Study in Implementation.Journal of Research Administration, 48(1):86.

3. Daher G P.(2017)Shared service centre business model - analysis of factors that influence 
standardization.Social Science Electronic Pubishing, 01(3):31-37.

4. Zhang,Yanhui. (2019) Research on the changes brought about by the financial shared service model for business management. Finance and Economics, (03):137-138.

5. Squilla Betal.(2017)Research Shared Services:A Case Study in Implementation.Journal of Research Administration ,48(1):86. 